\title{
FOTO
}

\section{Las calificaciones del Consejo de Censura Cinematográfica de Chile entre 1960 y 1973. Un estudio sobre la cambiante recepción cinematográfica}

\section{The ratings of the Chilean Film Censorship Board in 1960-1973. A study on the changing film reception}

\author{
Jorge Iturriaga Echeverría \\ Universidad de Chile, Chile \\ jorge.iturriaga@uchile.cl
}

Francisca Torres-Cortés

London School of Economics and Political Science, Reino Unido

f.j.torres@lse.ac.uk.

\begin{abstract}
Resumen:
El objetivo de este texto es describir cuantitativamente el trabajo del Consejo de Censura Cinematográfica de Chile entre 1960 y 1973 (período enmarcado por la vigencia del Decreto $\mathrm{n}^{\circ} 37$ de 1959), a partir de la información contenida en más de seis mil actas de calificación de largometrajes. Se sostiene que la clasificación de películas por parte del Consejo se enfocó en la exclusión de los públicos menores de edad, más que en la prohibición total de contenidos. Sin embargo, se observó una amplia variación de las calificaciones en función de factores como período de gobierno, compañía distribuidora, tópicos cinematográficos e integrantes del Consejo, lo que apunta a que el CCC no desplegó una labor homogénea e inmutable en el período analizado.
\end{abstract}

\begin{abstract}
:
The goal of this text is to quantitatively describe the work of the Chilean Film Censorship Board between 1960 and 1973 (period framed by the validity of Decree $\mathrm{n}^{\circ} 37$ of 1959), based on the information of more than six thousand film rating documents. It is argued that the classification of films by the Board focused on the exclusion of minors, rather than total banning of contents. However, there was a wide variation in the ratings based on factors such as government period, distributors, cinematographic topics and members of the Board, which indicates that the CCC did not display a homogeneous and immutable work during the analyzed period.
\end{abstract}

Palabras clave:

Cine; censura; consejo de censura; calificación cinematográfica; historia del cine; Chile.

Keywords:

Cinema; censorship; censorship board; film ratings; history of cinema; Chile. 


\section{Introducción. Deconstruyendo el Consejo*}

En el imaginario liberal dominante se tiende a pensar a la cultura masiva como un espacio abierto, de intercambios fluidos, donde el protagonismo lo llevan los privados y el Estado se limita a cumplir un rol de fomento. En general se tiende a soslayar los mecanismos supresivos y de control que están detrás de las esferas culturales modernas. En un trabajo anterior (Iturriaga, 2015) pudimos dimensionar empíricamente el considerable peso que tuvieron las herramientas de control en la configuración del campo cinematográfico. Los resultados establecieron que la censura cinematográfica ${ }^{1}$ se originó en las primeras décadas del siglo XX en Chile como una herramienta de civilización e higiene, que la élite entendía como defensa del orden oligárquico, patriarcal y católico, frente a un estímulo que, entre otras cosas, proyectaba historias de desobediencia a la ley, comedias irrespetuosas hacia la autoridad, imágenes "sensuales" y formas más abiertas de entender las relaciones familiares, el cuerpo y la moral. La nueva herramienta censora, sumada a otros factores, encauzó a la esfera cinematográfica, centralizándola, sometiéndola a vigilancia estatal, arrinconando los contenidos disruptivos y segregando a los públicos subalternos que se habían tomado el espacio, como los niños y las mujeres. Entrando en la segunda mitad del siglo, en otro trabajo (Iturriaga \& Donoso, 2018) detectamos que el impacto del Consejo de Censura Cinematográfica (CCC) sobre la esfera cinematográfica se mantenía en términos generales. Sin embargo, nos

\footnotetext{
* Este artículo es resultado de los proyectos "La censura cinematográfica en Chile 1960-200o", Fondecyt Iniciación $\mathrm{n}^{\mathrm{0}} 11170598$ (Agencia Nacional de Investigación y Desarrollo) y "La censura cinematográfica en Chile 1960-1973", U-Inicia $\mathrm{n}^{\circ} 007 / 17$ (Vicerrectoría de Investigación y Desarrollo, Universidad de Chile). Este texto no habría sido posible sin el trabajo del equipo conformado por Karen Donoso, Camilo Matiz, Camila Magnet y José Luis Cañas.

1 Entendemos por censura cinematográfica la revisión previa de películas por parte de un organismo centralizado (de gestión estatal o privada) reconocido como oficial, con el fin de determinar si procede su circulación en el territorio (es decir con la facultad de prohibir y requisar una obra completa) y en qué circunstancias (supresión de escenas, exclusión de públicos, salas u horarios especiales, etc.). Comúnmente se diferencia este sistema al denominado de calificación, donde el organismo solo se limita a establecer las condiciones de circulación de la obra, sin posibilidad de prohibición. En Chile existió censura cinematográfica entre 1925 y 2003, año en que se adoptó un sistema de calificación (sin embargo el Consejo de Censura cambió de nombre en 1974, cuando fue rebautizado Consejo de Calificación Cinematográfica).
} 
percatamos que no se trataba de una institucionalidad monolítica, sin matices ni variaciones. Vimos que la conflictividad pública fue mucho más marcada durante el gobierno de Jorge Alessandri (1958-1964) y que se había reforzado debido a la promulgación de una nueva ley en 1959, que el gobierno había dictado por considerar que se estaba frente a una oleada de "inmoralidad cinematográfica” sin precedentes. Por otro lado, se pudo comprobar que las posturas frente a la censura cinematográfica eran diversas, habiendo quienes la apoyaban incondicionalmente, quienes la apoyaban con reparos y quienes la rechazaban de plano.

Esta perspectiva que se abrió estaba en plena coherencia con una concepción flexible de la censura, planteada por Biltereyst y Vande Winkel (2013, p. 3). Los autores sostienen que la visión dominante asume la existencia de un todopoderoso control "institucional-prohibitivo", donde se enfatiza la verticalidad del proceso de vigilancia, que está además centrado en el castigo. Una noción más abierta concibe a la censura como un campo de "negociación” y lucha, en el sentido de entender que la censura no es una suerte de máquina autómata de supresión de contenidos, sino un espacio donde las diversas visiones hegemónicas confluyen y se confrontan, donde participan no solo funcionarios del Estado y representantes religiosos, sino también la sociedad civil (empresarios, profesionales, padres de familia, etc.) ${ }^{2}$ y donde los mecanismos de acción trascienden a la mera prohibición de contenidos. En esa línea se inserta el presente texto, buscando trazar el comportamiento del CCC bajo tres gobiernos de muy distinto signo político (derecha, centro e izquierda, respectivamente), para ofrecer un retrato multidimensional de una institución que no operaba en el aire sino, de hecho, en estricta vinculación con fuerzas vivas de la sociedad. El desafío es considerable puesto que la principal publicación existente sobre la historia del Consejo de Censura Cinematográfica de Chile participa fuertemente de una visión monolítica. En Pantalla Prohibida,

${ }^{2}$ Ver por ejemplo Ramírez (2016), donde se parte de la base que la censura cinematográfica en Argentina consistió en la articulación entre Estado, iglesia católica y empresariado. 
Olave y De la Parra (2001, contraportada) conciben al CCC como una máquina de eliminación de contenidos, al presentar una "crónica de las innumerables arbitrariedades, errores e injusticias cometidas durante décadas en Chile en nombre de la censura”. Se trata de una perspectiva unilateral que se resiste a la comprensión compleja de una institución histórica. De hecho, el texto consiste fundamentalmente en una descripción de las películas prohibidas, es decir se perfila al CCC en ausencia, sin abordarlo con propiedad.

Así como creemos necesaria esta interrogación histórica a la institución censora, también queremos enriquecer los análisis relativos a la historia del cine, en línea con lo que se ha denominado "new cinema history" (Maltby, Biltereyst \& Meers, 2011). Contra el sentido común que asegura que las bases de la comprensión de las cinematografías residen en los autores y las obras (tomados de manera individual), nuevas tendencias apuntan a levantar el vínculo entre el cine y los públicos. Como señala Maltby (2011, p. 32) es atender más a "las personas" que a los "artefactos", estudiando las "condiciones culturales de recepción” como “contrapunto" a la primacía de los análisis textuales (la traducción es nuestra). En ese sentido el CCC es aquí tomado no solo como institución política y supresiva, sino también como un colectivo que emite interpretaciones fílmicas, al poner diversas etiquetas legales a los contenidos. Y la apuesta del presente estudio es trazar esa recepción de manera sistemática y consistente (gran escala) y no seleccionando elementos ocasionales y excepcionales.

El presente trabajo, entonces, pesquisó los documentos del CCC con una doble misión: deconstruir histórica e internamente a la institución y cuantificar los diversos resultados de su trabajo calificador. A partir de ahí las preguntas que se plantearon fueron las siguientes:

- ¿ ¿A través de qué herramientas el Consejo de Censura clasificó e intervino el mercado cinematográfico de los años ‘6o?

- $\quad$ ¿Esa intervención fue consistente y regular a lo largo del período? 
- ¿ ¿La labor del Consejo varió de acuerdo a los diferentes agentes y productos cinematográficos?

- ¿Sus integrantes mostraron un comportamiento homogéneo y unitario o existieron disensos y diferencias internas?

A partir de un análisis sistemático de las actas de calificación del período 19601973, se sostiene que el impacto del CCC fue considerable en términos de separación de públicos por edad (más que por prohibición de contenidos) y que esos resultados variaron bastante en función de factores como gobiernos, distribuidores, tópicos cinematográficos e integrantes del Consejo. En ese sentido, este estudio ofrece una muestra concentrada de cuan cambiante pueden ser la recepción fílmica, al interior de un conglomerado reducido y normado en torno a una misión específica.

\section{Marco metodológico: las actas de calificación}

El presente trabajo estudia las actas de calificación de películas de una institución destinada desde 1925 a filtrar fundamentalmente los contenidos de sexualidad y criminalidad, sea, según la ley, prohibiendo "las películas contrarias a la moral, a las buenas costumbres o al orden público”, sea calificando para mayores de edad a aquellas en que "se exalte (...) los aspectos sexuales, los hechos delictuosos u otras manifestaciones de conducta irregular" (DFL 37, 1959). El cuerpo legal no entregaba más detalles que eso. Evidentemente, se trataba de un diseño abierto a la discrecionalidad, como casi todos los sistemas de censura (Ethis, 2014). Sin embargo, el CCC estaba lejos de ser un organismo demasiado autónomo. Financiado por privados (los distribuidores, que pagaban una suma por cada película ingresada para revisión) pero dependiente del Ministerio de Educación, el Consejo implementaba una censura fundamentalmente gubernamental. La mayor parte de sus integrantes eran nombrados directamente por el Presidente de la República o por funcionarios directivos nombrados por él. El Congreso Nacional 
nunca tuvo representación alguna (llamativo, pues incluso la Municipalidad de Santiago pudo nombrar integrantes). Es más, durante casi toda la década de 1940, el CCC fue parte del Ministerio del Interior. Las otras representaciones al interior del Consejo provenían de instituciones del campo de la educación: universidades y asociaciones de padres/apoderados. ¿El mundo cinematográfico? Nunca fue convocado formalmente sino hasta 1974, en los albores de la dictadura militar, cuando se institucionalizó la presencia de “críticos cinematográficos” en representación del Colegio de Periodistas. ¿La iglesia católica? Tuvo representación, pero de manera intermitente e indirecta, sea con representantes de "padres de familia" (a través de la Federación de Padres y Apoderados de Establecimientos Particulares, que hasta 1966 solo acogió a colegios católicos), sea con representantes de la Universidad Católica.

El período escogido para este estudio está enmarcado por un encuentro entre dos fuerzas. Por un lado, se trata de una época marcada por una distensión cinematográfica a nivel global, caracterizada por la decadencia del cine clásico de grandes estudios, el surgimiento de "nuevos cines" y la sustitución del sistema de censura por uno de calificación según edades en el mercado más fuerte del espacio occidental, EE.UU. Por otro lado, el período se abre con la promulgación del Decreto con Fuerza de Ley $n^{\circ} 37$ (diciembre de 1959) por el gobierno del independiente de derecha Jorge Alessandri, una legislación considerada lesiva y restrictiva por varios actores de la esfera cinematográfica. El decreto vino a modificar, por primera vez desde 1925, las categorías de calificación, multiplicando y elevando los umbrales de edad. La intención explícita era buscar proteger ya no solo a la niñez sino además a "la juventud": se reemplazaron las cuatro principales categorías existentes (para mayores y menores; para mayores de 15 años; para mayores de 15 y no recomendable para señoritas; y rechazada) por otras cinco (mayores y menores; mayores de 14; mayores de 18; mayores de 21; y rechazada)3. En términos de la composición del

3 La categoría Para Mayores de 21 fue creada en abril de 1960. Además de esas categorías, desde 1953 existió "aprobada con carácter educativo", la que se podía añadir a obras calificadas para 
Consejo, la nueva legislación reforzó el control del Poder Ejecutivo y reincorporó la representación católica (abandonada en 1953). El Decreto $\mathrm{n}^{\circ} 37$ estableció que el Presidente de la República elegiría directamente a tres de los siete integrantes y en base a ternas externas a los otros cuatro miembros. Los tres primeros consistían en el Director General de la Dirección de Bibliotecas, Archivos y Museos (quien preside el Consejo, la norma desde 1925), un siquiatra y un ex juez de tribunales superiores. Los cuatro restantes serían electos por el primer mandatario en base a ternas propuestas por la Universidad de Chile, la Universidad Católica (no se especificaba profesión o área de estos representantes universitarios), asociaciones de padres y apoderados de colegios fiscales y asociaciones de padres y apoderados de colegios privados.

El trabajo de esta institución en el período 1960-1973 se vio reflejado en un universo total de 6130 actas de sesiones de calificación de material fílmico. En cada una de esas sesiones 4 los consejeros generalmente alcanzaban a revisar y calificar dos largometrajes y un paquete de cortometrajes (ver imagen $\mathrm{n}^{\mathrm{o}} 1$ ). Mediante la ley de Acceso a la Información Pública, el actual Consejo de Calificación Cinematográfica ha cedido a esta investigación esas actas de calificación, en fotografías digitales, ordenadas en carpetas por mes y año. Se decidió trabajar exclusivamente con los largometrajes de soporte fílmico y destinados para exhibición pública, es decir se excluyeron cortometrajes (por la irregular información de sus títulos) y películas para televisión o para exhibición particular (por corresponder a actividades con condicionantes estructuralmente diferentes). Bajo esos parámetros se llegó a un total de 5695 largometrajes revisados por el CCC. Cada calificación de material registrada en el acta ofrece ocho categorías de información relevante: fecha (además de lugar y hora); tipo

mayores y menores, para 14 o para 18 . Por otro lado, el decreto $\mathrm{n}^{\circ} 37$ al parecer puso término a una de las herramientas más asociadas a la censura, los cortes de escena. Establecidos en la ley de 1928 ("arreglos y modificaciones") fueron eliminados en 1953, sin embargo todavía en 1959 era común leer en prensa sobre su utilización. En cambio, con posterioridad a esa fecha se han encontrado muy pocas menciones.

4 El Consejo operaba generalmente de lunes a viernes (aunque no era excepcional el funcionamiento los sábados en la mañana), con una sesión de mañana y otra de tarde, de enero a diciembre (con un receso casi total en febrero). 
de metraje ("película" o "noticiero, corto, sinopsis"); nombre de la película; nombre de la entidad distribuidora (no siempre rellenado); nombre/firma del revisor; calificación emitida por cada revisor; nombre del presidente de la sesión; y nombre del secretario/a de la sesión. El acta incluye una sección llamada "observaciones", sin embargo son muy escasas las oportunidades en que los revisores dejaban comentarios. A partir de una base de datos construida con esas categorías de información, esta investigación se centró en analizar el trabajo calificador del Consejo en base a su evolución en el tiempo (fechas), las cinematografías revisadas (distribuidores y tópicos sugeridos por sus títulos) y la identidad de los consejeros.

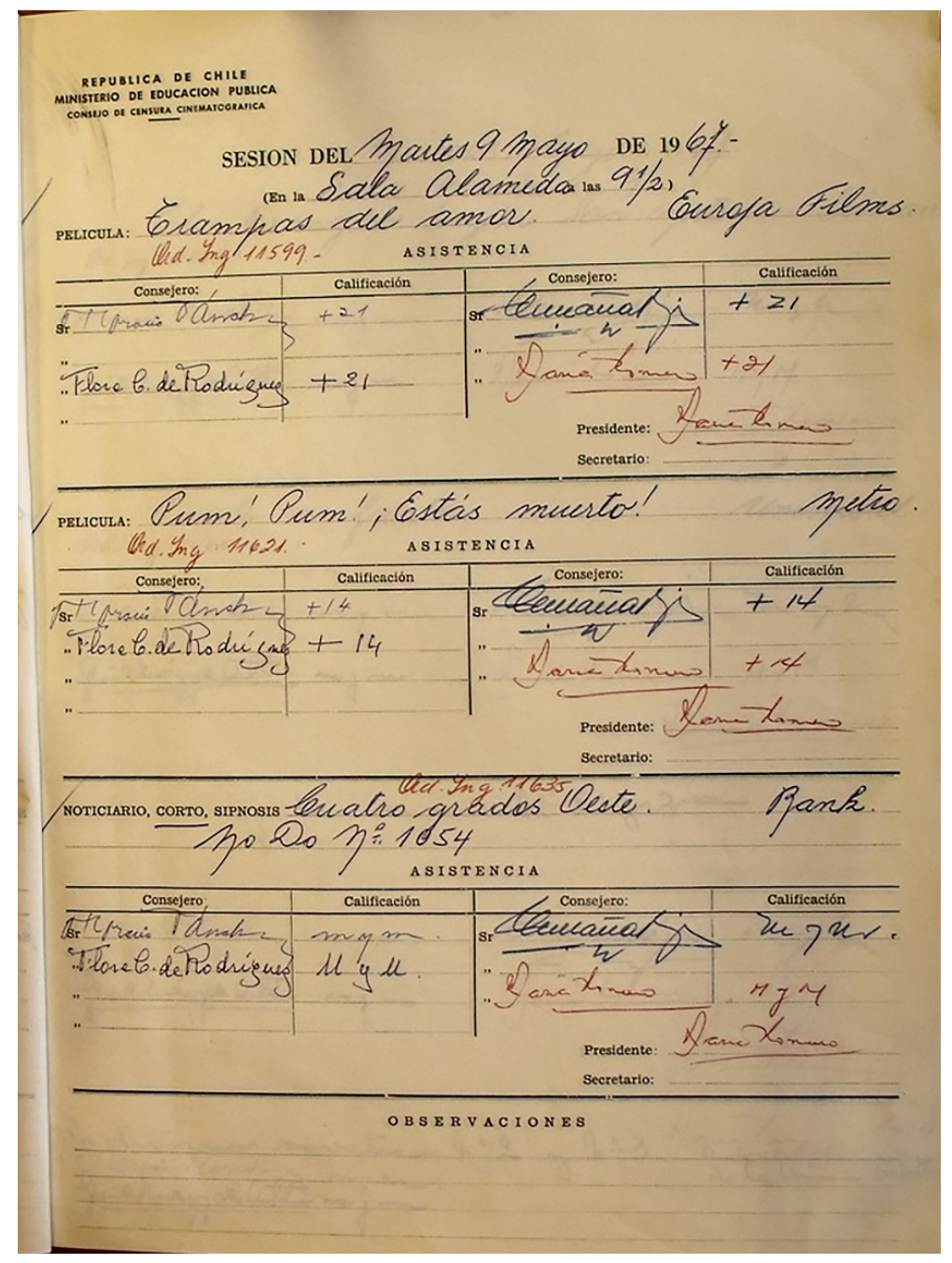

Imagen $\mathrm{n}^{\circ}{ }^{1}$. Acta de calificación del 9/5/1967 


\section{Análisis de las actas de calificación}

\subsection{Caracterización de la actividad cinematográfica y censora, 1960-} 1973

\subsubsection{Tamaño y evolución}

En el período de estudio ingresaron y fueron revisados por el Consejo de Censura 5695 largometrajes, dando un total de 5560 con revisiones válidas (excluiremos en la mayor parte de los análisis 110 películas calificadas con empate o pendiente y 25 sin calificación) 5 . Aquella cifra da un importante promedio de 406 obras revisadas por año, más de una por día. Junto con el tamaño, el mercado cinematográfico se caracterizó por ser dinámico, pues el período está marcado por una sucesión de alzas y caídas bastante pronunciadas (ver gráfico $\mathrm{n}^{\mathrm{o}} 1$ ). La tendencia general apunta a una baja en la cantidad de películas en circulación. Hacia el final del período el mercado de películas era aproximadamente tres veces más pequeño que al iniciarse la década de 1960. Se puede explicar este gráfico con factores externos e internos. En relación a lo foráneo, la tendencia no resulta muy distinta a lo que se puede encontrar en otras latitudes. En estos años gran parte del mundo occidental vio decaer la actividad cinematográfica en sus indicadores más importantes: cantidad de películas realizadas, cantidad de salas existentes, asistencia de público y recaudaciones por taquilla. Generalmente se atribuyen estas caídas al surgimiento y masificación de la televisión. Sin embargo hay que mencionar también el fin del sistema de estudios integrado verticalmente en Estados Unidos (cuando la Corte Suprema de ese país forzó a las grandes compañías a vender sus teatros) lo que generó un nuevo marco de producción focalizado en la factura de menos películas pero de mayor presupuesto (Black, 1999). En cuanto al factor interno, es necesario mencionar que entre 1971 y 1973 el declive en el ingreso de películas tuvo como fuerza adicional el boicot que los majors estadounidenses realizaron al gobierno socialista de Salvador Allende.

5 Los gráficos $\mathrm{n}^{\circ} 1,3$ y 10 se basan en el total de cintas revisadas; el resto de gráficos tiene como universo las 5560 películas con calificación válida. 
Efectivamente, entre agosto de 1971 y diciembre de 1973, no ingresó prácticamente ninguna película proveniente de alguna de las siete principales compañías hollywoodenses. Ahora bien, ese boicot tampoco explica toda la tendencia, pues una vez reingresado Hollywood al país en 1974, el mercado volvió a los niveles de fines de los 60 (en torno a los 350 cintas por año), pero no se acercó nunca a los de inicios de la década (50o películas por año).

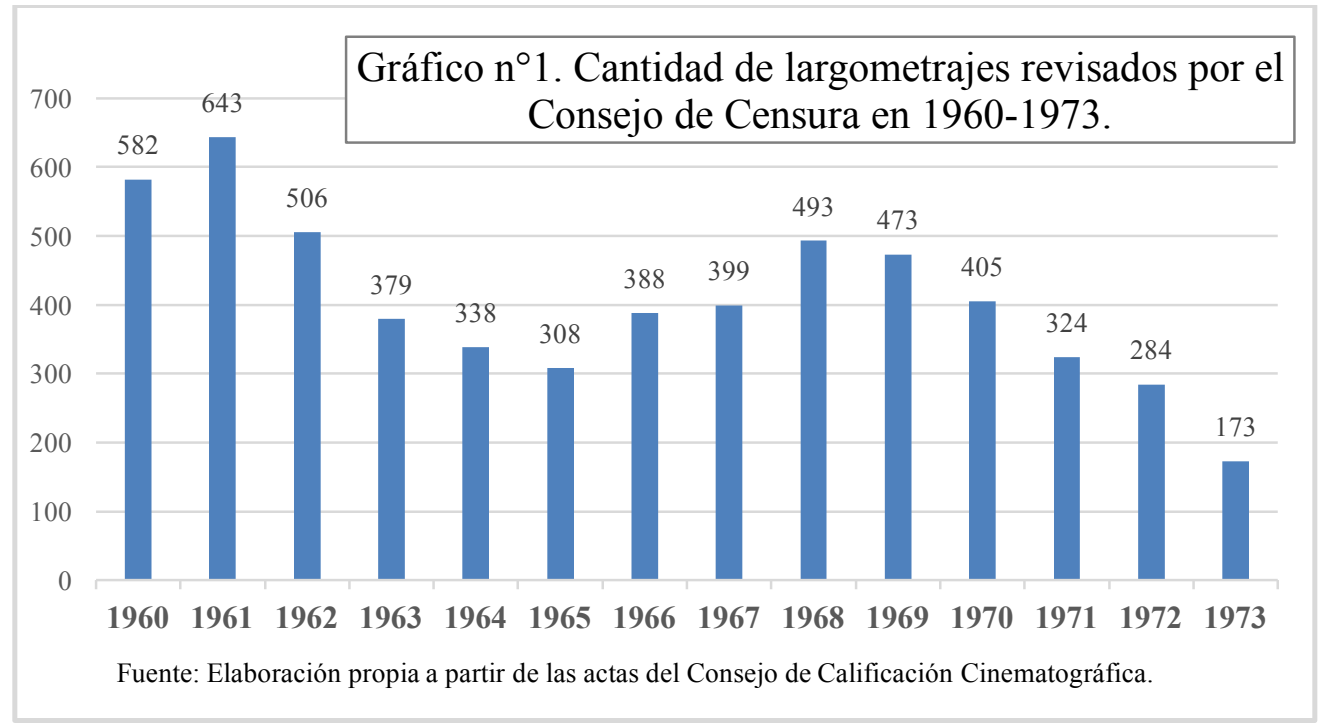

\subsubsection{Distribución cinematográfica}

Como ha sido la norma en casi todo el globo cinéfilo, la actividad estuvo fuertemente dominada por las compañías distribuidoras de origen estadounidense (ver gráfico $\mathrm{n}^{\circ} 2$ ). De las diez entidades con más material revisado por el Consejo en este período, siete fueron de EE.UU., a saber, en orden decreciente, Metro-Goldwyn-Mayer, Columbia, United Artists, Paramount, Fox, Warner Bros. y Universal. Claramente se trataba de una estructura oligopólica del mercado, por cuanto esas siete compañías representaban el 43,8\% de las películas revisadas, mientras todo el resto, alrededor de 170 distribuidores, fue responsable del 52,5\% de la actividad ${ }^{6}$. En todo caso, vale la pena destacar ciertos elementos que hablan de diversidad. De las veinte entidades con mayor actividad, ocho eran chilenas. La tercera ${ }^{6} \mathrm{El}$ 3,7\% restante de películas calificadas no incluía información sobre la distribuidora. 
compañía más fuerte del período fue la mexicana Pelmex. Y en $17^{\circ}$ lugar encontramos nada menos que a la embajada de la Unión Soviética, con un volumen de cintas superior al de cualquier otra misión diplomática (y operativa no solo en los años de la Unidad Popular). Si bien el dominio de las siete empresas señaladas resulta abrumador, es importante dimensionarlo en términos históricos. Estamos hablando, quizás, del período donde el dominio hollywoodense fue menos intenso, muy lejos por ejemplo del 90\% del mercado que poseía a comienzos de la década de 1930 (Iturriaga, 2015, p. 303). Según Paranaguá (2003, p. 91), comparadas con otros períodos del siglo XX, las décadas de 1960 y 1970 mostraron los números más bajos en el predominio yankee de las carteleras latinoamericanas.

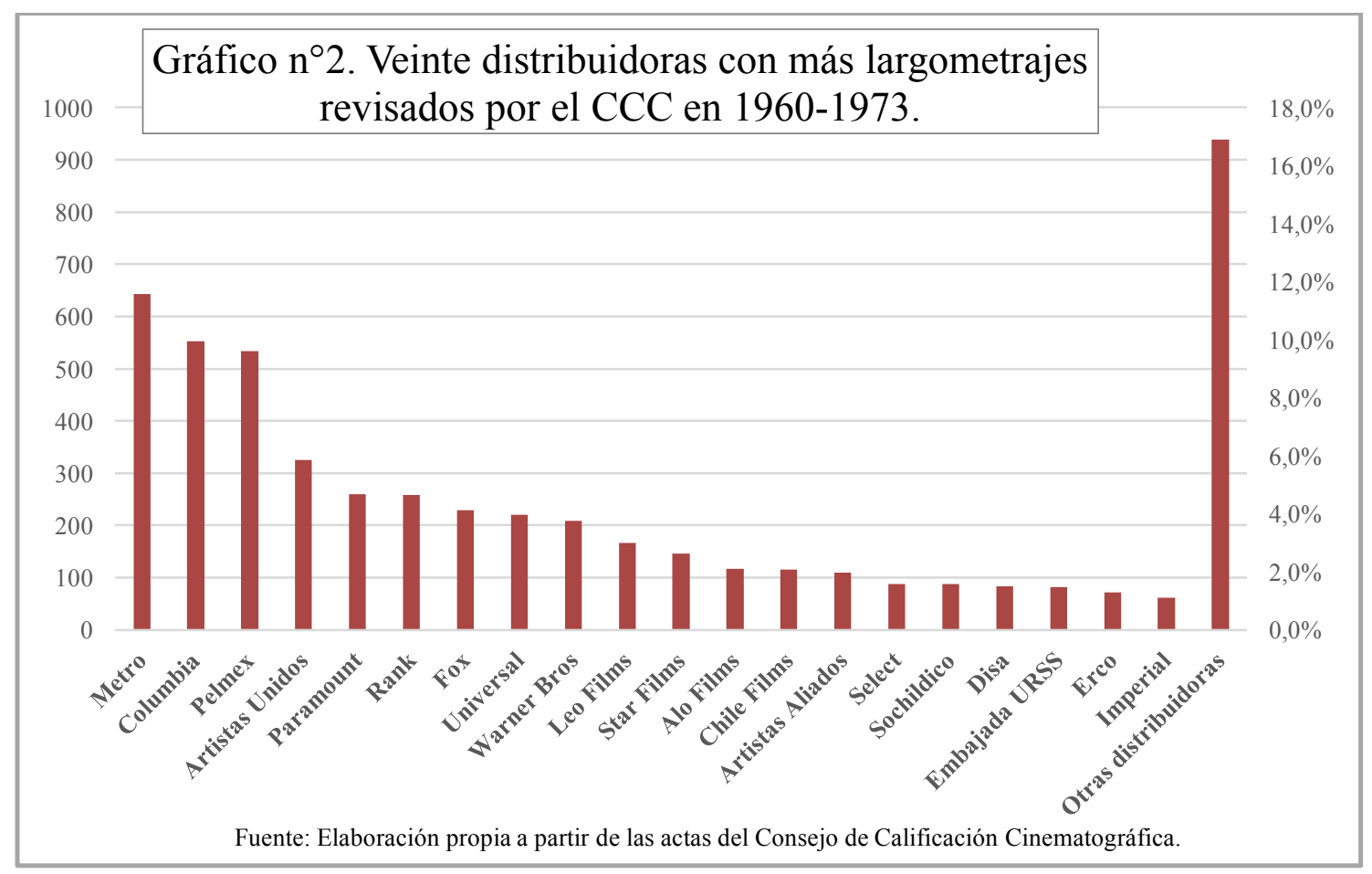

\subsubsection{Palabras clave de los títulos}

¿Qué material traían estos distribuidores? El período escogido es de crucial importancia en la historia del cine, por cuanto consistió en un momento de apertura en términos institucionales, estéticos y temáticos. El fin de la censura previa en Estados Unidos (y su reemplazo por un sistema de calificación por 
edades), la masificación de los géneros llamados exploitation (sexo y violencia) y la diversificación estética más allá de la narración tradicional configuraron un escenario de apertura cultural que es recordado hasta el día de hoy como un cambio de época. De hecho así fue percibido el fenómeno en Chile en los años 60 (Iturriaga \& Donoso, 2018). Para tener una noción general de cuál fue el tipo de material cinematográfico introducido en este período, decidimos contar las palabras más comunes en los títulos revisados (ver tabla $\left.\mathrm{n}^{\circ} 1\right)^{7}$. Seleccionamos las veinte palabras más presentes en los nombres de largometrajes (palabras compuestas por al menos cuatro letras) en orden a asignarle una connotación. Llama la atención la importante presencia de palabras que en grueso (por supuesto, asumiendo la posibilidad de usos metafóricos y no literales) sugieren crimen y violencia, como "muerte", "matar", "sangre", "venganza", "guerra", "pistola" y "asesino". Hay otras palabras que no son unívocas de ninguna manera, pero que, más adelante veremos, su calificación sugiere connotación erótica, como "amor" y "mujer".

\begin{tabular}{|l|c|c|}
\hline \multicolumn{1}{|c|}{ Palabra(s) } & $\begin{array}{c}\text { Cantidad } \\
\text { de } \\
\text { películas } \\
\text { (unidades) }\end{array}$ & $\begin{array}{c}\text { Porcentaje } \\
\text { en relación } \\
\text { a total de } \\
\text { títulos del } \\
\text { periodo }\end{array}$ \\
\hline amor(es) (amorosos, etc) & 194 & $3,5 \%$ \\
\hline hombre(s) & 123 & $2,2 \%$ \\
\hline mujer(es) & 100 & $1,8 \%$ \\
\hline noche(s) (medianoche) & 94 & $1,7 \%$ \\
\hline muerte (muerto, muertos, mortal) & 91 & $1,7 \%$ \\
\hline mundo (mundial) & 61 & $1,1 \%$ \\
\hline vida(s) & 62 & $1,1 \%$ \\
\hline matar (maté, mató, matarás, etc.) & 58 & $1,1 \%$ \\
\hline tres & 58 & $1,1 \%$ \\
\hline diablo(s) (diabólico/a) & 56 & $1,0 \%$ \\
\hline sangre (sangriento/a) & 54 & $1,0 \%$ \\
\hline venganza (vengador) & 52 & $0,9 \%$ \\
\hline guerra (guerrero, guerrillero) & 50 & $0,9 \%$ \\
\hline gran (grande) & 48 & $0,9 \%$ \\
\hline
\end{tabular}

\footnotetext{
7 En todas las tablas de este texto el total considerado es de 5495 títulos únicos, pues se omitieron las duplicaciones de títulos (segundas o terceras revisiones por desempate o reconsideración).
} 


\begin{tabular}{|l|c|c|}
\hline infierno / infernal & 45 & $0,8 \%$ \\
\hline vivir (viva, vive, vivo, etc) & 44 & $0,8 \%$ \\
\hline joven/jóvenes (juventud) & 44 & $0,8 \%$ \\
\hline pistola (pistolero) & 43 & $0,8 \%$ \\
\hline asesino (asesinato) & 42 & $0,8 \%$ \\
\hline hijo/a(s) & 41 & $0,7 \%$ \\
\hline TOTAL & $\mathbf{1 3 6 0}$ & $\mathbf{2 4 , 7 \%}$ \\
\hline
\end{tabular}

Tabla $\mathrm{n}^{\circ} 1$. Veinte palabras más comunes en títulos de largometrajes, 1960-1973

Más allá de las especulaciones, podemos perfilar el carácter de estas películas mediante comparación cuantitativa. Tenemos la lista de veinte palabras más comunes en los títulos para la década siguiente (1974-1983), período igualmente (o más) marcado a nivel internacional por la masificación de las temáticas sexuales y violentas, pero desarrollado bajo dictadura militar. En términos generales este segundo período también está cargado de vocablos que sugieren emociones fuertes. De las doce palabras recién mencionadas, la primera década en dictadura contiene diez (no aparecen entre las veinte más comunes "pistola" ni "sangre"). De las diez palabras comunes en los dos períodos nueve tienen mayor peso proporcional en 1960-1973 que en 1974-1983. En total, esas diez palabras representan el 14,2\% de los títulos únicos revisados por el Consejo en el primer período y un 10,2\% en el segundo (diferencia de 28\%). Las diferencias más grandes se encuentran en "matar" (1,1\% frente a un $0,6 \%)$, "amor" (3,5\% frente a un 2\%) y "diablo" (1,0\% frente a un $0,6 \%)$.

\subsubsection{Consejeros}

Estas cinematografías fueron examinadas en 5695 revisiones del Consejo, en las cuales participaron un total de 58 consejeros, dejando un total de 23.402 firmas de asistencia. En el gráfico $\mathrm{n}^{\circ} 3$ se listan los 30 consejeros con más de 100 películas revisadas ${ }^{\mathbf{8}}$. Lo primero que llama la atención es la alta concentración de las tareas de revisión y calificación en un puñado de miembros. Destacan los tres consejeros más activos: Gloria Errázuriz, María Romero y Miguel Luis

\footnotetext{
${ }^{8}$ No hemos logrado identificar el nombre de todos los consejeros (en ese caso se han codificado sus identidades), ni podido construir los perfiles biográficos de una mayoría consistente. Solo sabemos la adscripción institucional de 21 miembros de la lista de los más activos.
} 
Amunátegui. Cada uno de ellos participó en aproximadamente el 40\% del total de visionados de películas en el período y en conjunto representan el $30 \%$ de todas las participaciones de consejeros. Si desglosamos las participaciones a lo largo del tiempo, veremos la existencia de una franja de consejeros de notoria ubicuidad. Cuatro estuvieron presentes en los tres gobiernos del período: María Irarrázaval, Lidia Olivares y las ya mencionadas Errázuriz y Romero. Y es importante saber que cinco consejeros volvieron a integrar el Consejo luego del golpe de Estado de septiembre de 1973: Miguel Luis Amunátegui, María Romero, Ana Llona, Flora Covarrubias y Roque Scarpa (los cuatro primeros están entre los diez más activos de 1960-1973).

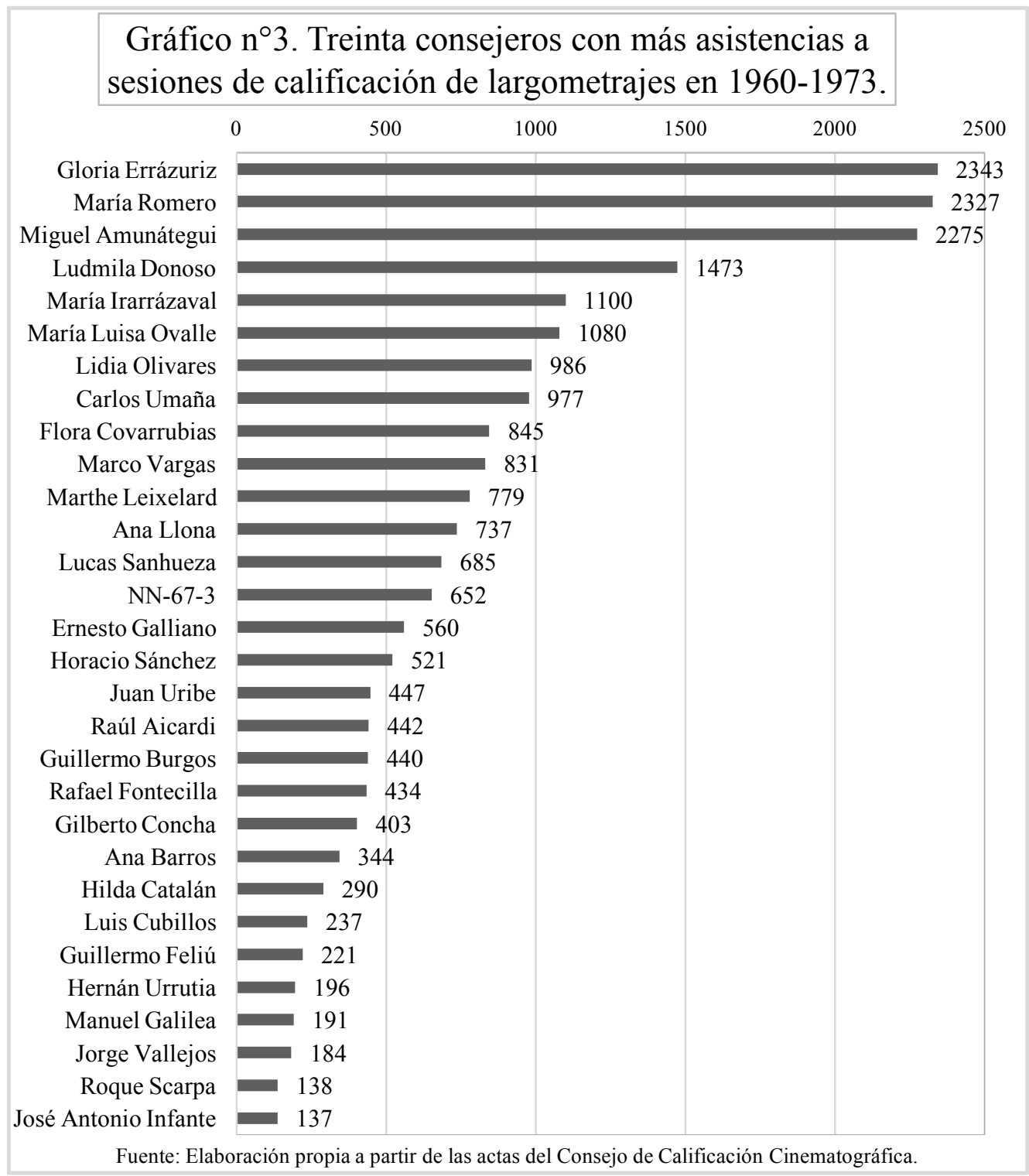


Pasando a una observación más cualitativa, es evidente reparar en la alta participación femenina. De los diez miembros con más revisiones, ocho son mujeres. Considerando el total de participaciones, nada menos que el $59 \%$ fue femenino. Este factor de diversidad, sin embargo no va correlacionado con diversidad sociocultural. De los seis consejeros más activos del período, dos representaban a la Universidad Católica (Gloria Errázuriz y María Luisa Ovalle) y dos a la Federación de Padres y Apoderados de Establecimientos Particulares (Miguel Luis Amunátegui y María Irarrázaval), es decir cuatro de los seis primeros representaban la orientación católica. Sorprende también que solo dos consejeros tuvieran vinculación directa con el mundo audiovisual: Raúl Aicardi (director del canal de TV de la Universidad de Chile en ese momento) y María Romero (directora de la revista cinematográfica Écran entre 1939 y 1960). En términos de status al interior del Consejo, se advierte que los presidentes titulares del organismo (en tanto directores de la Dirección de Bibliotecas, Archivos y Museos) no tuvieron una presencia importante en las revisiones de películas. Guillermo Feliú (1960-1966), Roque Scarpa (1967-1971) y Gilberto Concha (1971-1973) ocupan lugares modestos de participación, aunque lo de Concha (más conocido con su alias literario "Juvencio Valle") es relativo porque en apenas dos años mostró un compromiso importante. El trabajo de encabezar las sesiones fue mayormente realizado por un grupo distinto al titular. Con más de 300 presidencias encontramos a seis consejeros, que en conjunto presidieron el 60\% de los visionados: María Romero (1121 presidencias), el ex juez Lucas Sanhueza (622), el secretario de la DIBAM Ernesto Galliano (539), el ex juez Rafael Fontecilla (399), Gilberto Concha (388) y el ex juez Marco Vargas (368). A partir de todos estos datos, resulta evidente fijar la importancia de María Romero en el Consejo. Su prolongada y abultada presencia (integró el Consejo entre 1960 y 1971, con un receso en 1962-1963) y su rango (presidió cerca del 20\% de todos los visionados del período) la convierten en una figura ineludible. 


\subsection{Calificaciones realizadas por el CCC, resultados generales}

\subsubsection{Totales}

Analizar el trabajo calificador del Consejo exige una discusión preliminar en torno a las categorías de calificación por edades y su modificación legal en diciembre de 1959. De 1925 a 1959 la ley reconocía solo dos franjas de edad menores y mayores- siendo 15 años el límite entre uno y otro. A partir de 19591960 la ley estableció cuatro franjas, que llamaremos niñez (hasta 13), adolescencia (entre 14 y 17), juventud (de 18 a 20) y adultez (desde 21). El punto es que la mayoría de edad cinematográfica post 1959 fue pensada para los 18 años. La ley era explícita: "El Consejo calificará como inapta para menores de 18 años toda película en que se exalte en forma morbosa o nociva para la formación de la juventud, los aspectos sexuales, los hechos delictuosos $u$ otras manifestaciones de conducta irregular” (DFL 37, 1959). Es decir, la ley de 1959 elevó en tres años el umbral de mayoría de edad cinematográfica. Si en noviembre de 1959 la persona de 15 era considerada mayor y podía acceder a cualquier obra aprobada, a partir de 1960 tendría status de adolescente y tendría que sobrepasar aún dos categorías (cumplir seis años más) para acceder de lleno a la cartelera. En ese sentido, en este trabajo utilizaremos el umbral de los 18 años como criterio ordenador de los datos.

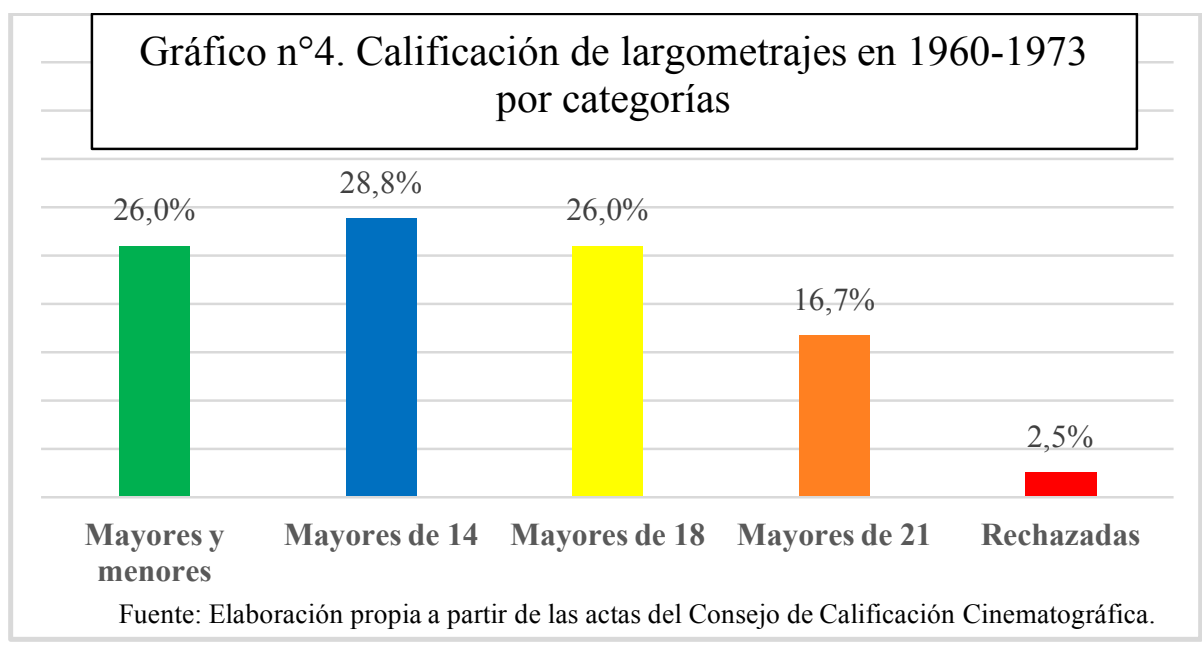


Los resultados del período 1960-1973 muestran una política de revisión bastante severa en relación a los públicos más jóvenes (gráfico nº4). De los 5560 largometrajes calificados por el CCC, el 54,8\% fue calificado para menores de edad (es decir sumadas la categoría Mayores y Menores y la Para Mayores de 14 Años); el 42,7\% fue calificado para mayores de edad (sumadas las categorías Para Mayores de 18 y Para Mayores de 21)9; quedando un 2,5\% en prohibición ${ }^{10}$. Entonces aquella imagen del cine como espacio transversal, donde todos los públicos se cruzan y comparten un lugar común, merece ser repensada, al menos para este período: casi la mitad de los largometrajes fue calificada para mayores de edad ${ }^{11}$. En relación a la prohibición de cintas, la tasa de rechazo de 1960-1973 parece marginal, 2,5\%, es decir una de cada cuarenta películas fue vetada por el CCC. Sin embargo no es justo dimensionar las 140 películas prohibidas en 1960-1973 exclusivamente en relación a las cifras de conjunto, pues bien sabemos que una sola obra fílmica puede generar oleajes culturales y políticos de gran magnitud. Más acá de los promedios y los totales, el impacto también debe ser evaluado en sus focalizaciones.

\subsubsection{Evolución}

Si desglosamos las calificaciones a lo largo del tiempo (gráfico $\mathrm{n}^{\circ} 5$ ) veremos algo de continuidad pero sobre todo mucho cambio. Solo vemos tendencia sostenida en que las películas para menores (salvo dos años) rara vez superan el 60\% y que las para mayores (salvo dos años) rara vez bajan del 37\%. Pero en general es bastante claro como las cinco categorías experimentan importantes variaciones año a año. Una manera de describir esos cambios es afirmando que la década de

\footnotetext{
9 En la actualidad se da una situación radicalmente distinta: de los 197 largometrajes revisados por el Consejo de Calificación Cinematográfica en los 10 meses previos a la escritura de este trabajo (octubre 2018 a julio 2019), tan solo el 5\% fue calificado para mayores de 18 años, siendo el $45 \%$ designado para todo espectador y el 50\% para mayores de 14 . Ver http://www.consejodecalificacioncinematografica.cl/

10 Añadamos que el calificativo de obra "educativa" fue utilizado en (tan solo) 81 oportunidades (66 veces para películas de Mayores y Menores, 13 veces para Mayores de 14 años y 2 para Mayores de 18).

${ }^{11}$ Ramírez (2013, p. 196) expone una situación similar para Argentina: en 1968 la censura estatal calificó para mayores de 18 a un tercio de las películas revisadas, proporción que aumentó a la mitad en 1973.
} 
1960 arranca y termina de forma estricta $(1961,1962$ y 1963 son los tres años con mayor proporción de rechazos) y que en el medio hay cierta liberalidad (en 1967 y 1968 los rechazos caen bastante, a la mitad e incluso a un cuarto del promedio del período, respectivamente). Destaca 1969 como el año más estricto de todos: el 53,7\% de los largometrajes fue timbrado para mayores de edad. Sin embargo, poco después, en 1972 y 1973, vemos la mayor apertura: en ambos años solo un tercio de las cintas fueron calificadas para mayores. A partir de este análisis, se instala una persistente sospecha: que el Consejo no era una máquina de calificaciones monolítica e inmutable.

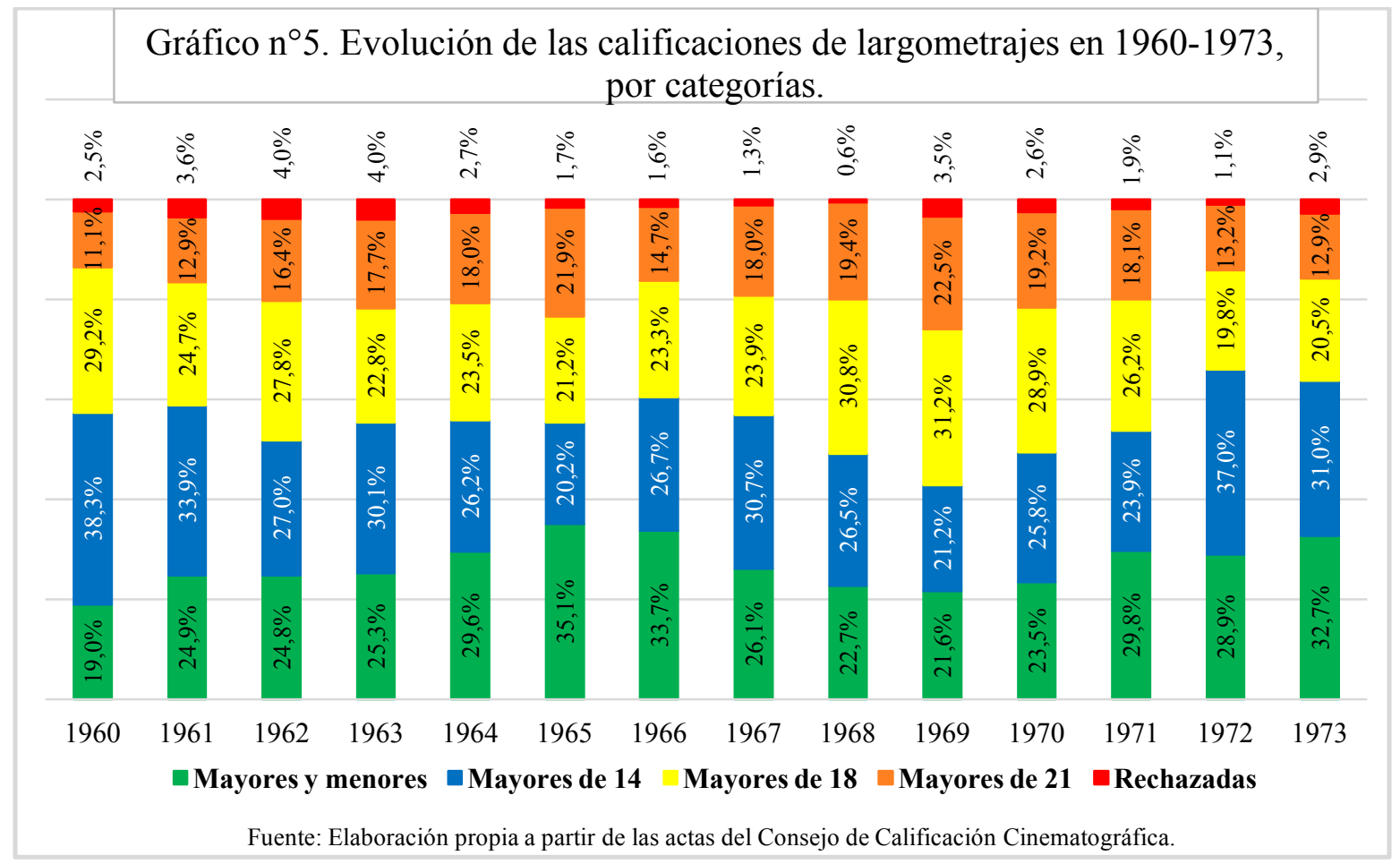

\subsection{Calificaciones realizadas por el CCC, según variables}

\subsubsection{Por gobierno}

Una manera de asentar la sospecha recién esgrimida es ordenando la evolución de las calificaciones en función de los tres gobiernos del período. Efectivamente el comportamiento de la censura varió bastante de gobierno en gobierno (ver 
gráfico $\left.n^{\circ} 6\right)^{12}$. Las diferencias más marcadas se dan entre los gobiernos de Jorge Alessandri y Salvador Allende, si tomamos las dos categorías más extremas. Bajo el primero se calificaron para todo espectador (solo Mayores y Menores) al 24,1\% de las películas ingresadas, mientras que en el segundo esa cifra subió a 30,9\% (aumento de un 28\%). En cuanto a la prohibición de películas, bajo Alessandri se rechazó el 3,3\% de los largometrajes revisados, mientras que con Allende esa cifra bajó a 1,6\% (caída de un 52\%). Sin embargo, si agrupamos las categorías en mayoría y minoría de edad, la zanja más grande se establece entre Frei y Allende. El gobierno demócrata cristiano tiene la tasa más baja de aprobación para menores $(51,5 \%)$ y la más alta para mayores $(46,5 \%)$, mientras el socialista tiene la más elevada de menores $(60,2 \%)$ y la más baja para mayores $(38,2 \%)$, lo que constituye diferencias de $+17 \%$ y $\quad-18 \%$ respectivamente.

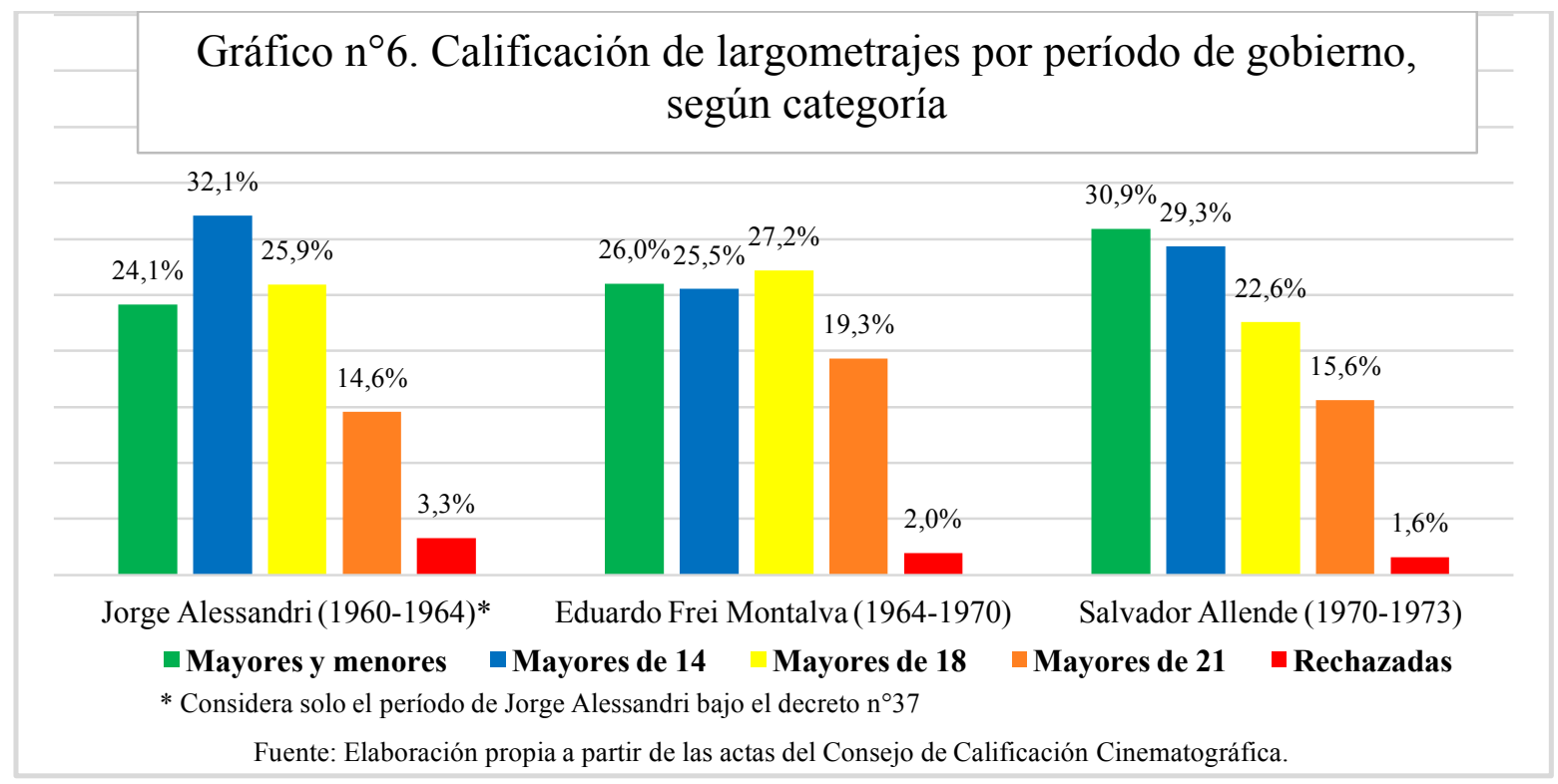

Un dato anexo reafirma la incidencia gubernamental. Si incluimos en el análisis el desempeño del Consejo con anterioridad a la vigencia del decreto $\mathrm{n}^{\circ} 37$, veremos una enorme variación en dos gobiernos distintos. Durante 1958 (10 meses bajo la presidencia del ex general de Ejército Carlos Ibáñez y 2 meses bajo

${ }^{12}$ En el caso de Jorge Alessandri no se incluye el período completo sino solo los cuatro años y medio bajo el mandato del Decreto ${ }^{\circ} 37$. 
Jorge Alessandri) se prohibieron dos largometrajes. Al año siguiente (11 meses bajo Alessandri, en el marco de la antigua legislación) fueron rechazadas nada menos que 23 películas.

\subsubsection{Por distribuidora}

Las calificaciones variaron bastante según la compañía propietaria del material revisado. En general las distribuidoras con mayor volumen de importación fueron calificadas más benevolentemente que las medianas y pequeñas. De las veinte entidades más activas en el período (gráfico $n^{\circ} 7$ ), las seis primeras tuvieron la mayor parte de su material calificado para menores de 18 años, en una proporción de 57,1\%. Las 14 restantes obtuvieron una tasa de calificación para menores de 18 del 51,5\% (un 10\% menos). Las diferencias se disparan en relación a la prohibición de películas. Las seis compañías más grandes tuvieron un $1,7 \%$ de rechazos, mientras que las 14 restantes obtuvieron un 2,6\% (alza de $53 \%)$.

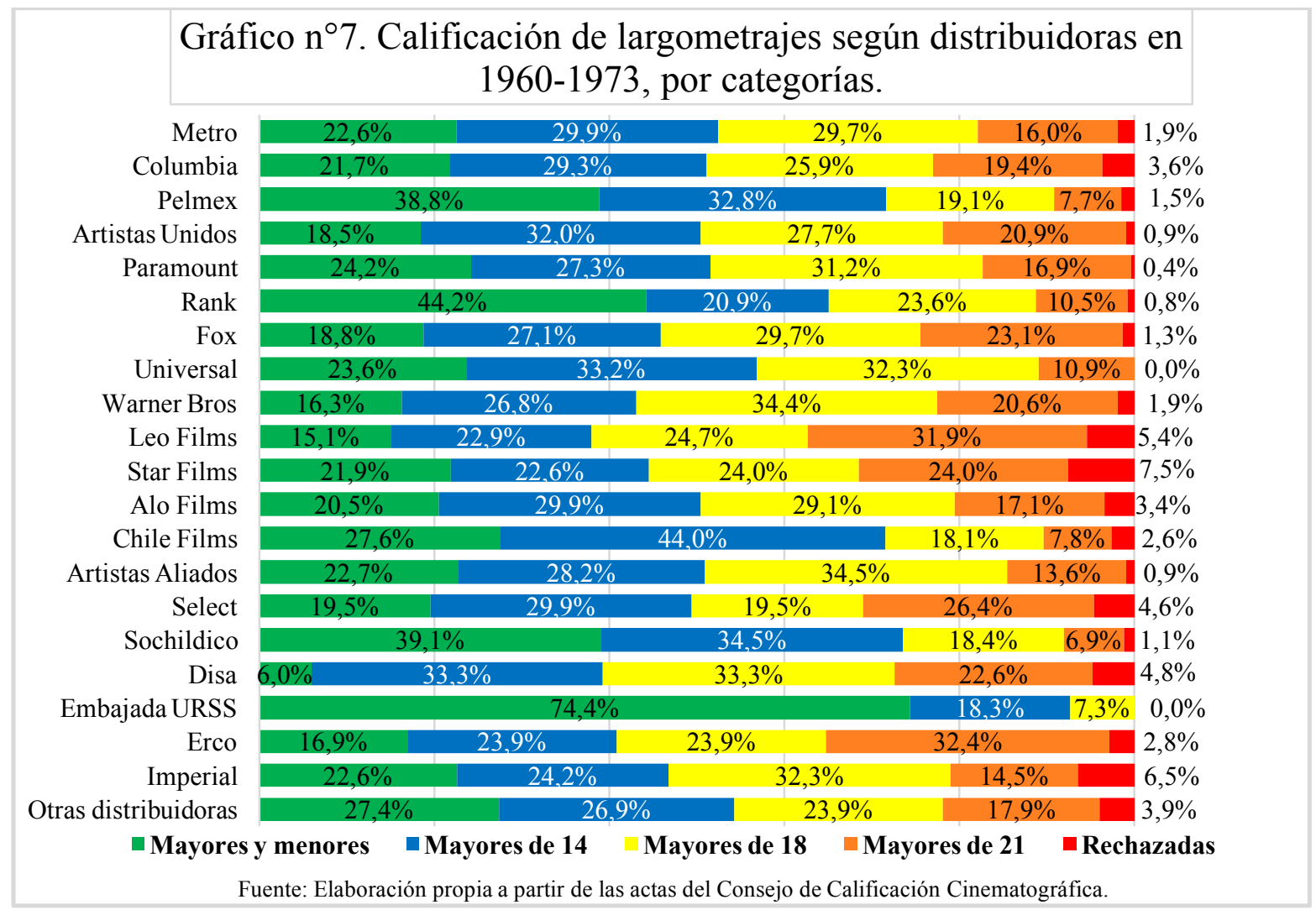


Para tener mayor precisión del sesgo hacia las distribuidoras, se interrogaron los datos buscando aislar al oligopolio estadounidense (ver gráfico $\mathrm{n}^{\circ} 8$ ). En primer lugar, agrupamos a las siete majors de Hollywood (MGM, Columbia, United Artists, Paramount, Fox, Warner Bros. y Universal), propietarias del 43,8\% de las películas ingresadas al Consejo. En segundo lugar, juntamos a todo el resto, exactamente 168 entidades, responsables del 52,5\% del mercado. Los resultados son ambivalentes. Por una parte, las compañías hollywoodenses tienen un nivel mayor de restricción por edad en sus películas: 47,5\% para mayores de edad versus $39,1 \%$ del resto de distribuidoras (diferencia de $-\mathbf{1 8 \%}$ ). Sin embargo, cuando se trata de prohibiciones de películas, la severidad se invierte: las corporaciones de EE.UU. fueron rechazadas en 1,8\%, mientras que el resto lo fue en $3,1 \%$ (aumento de $72 \%$ ).

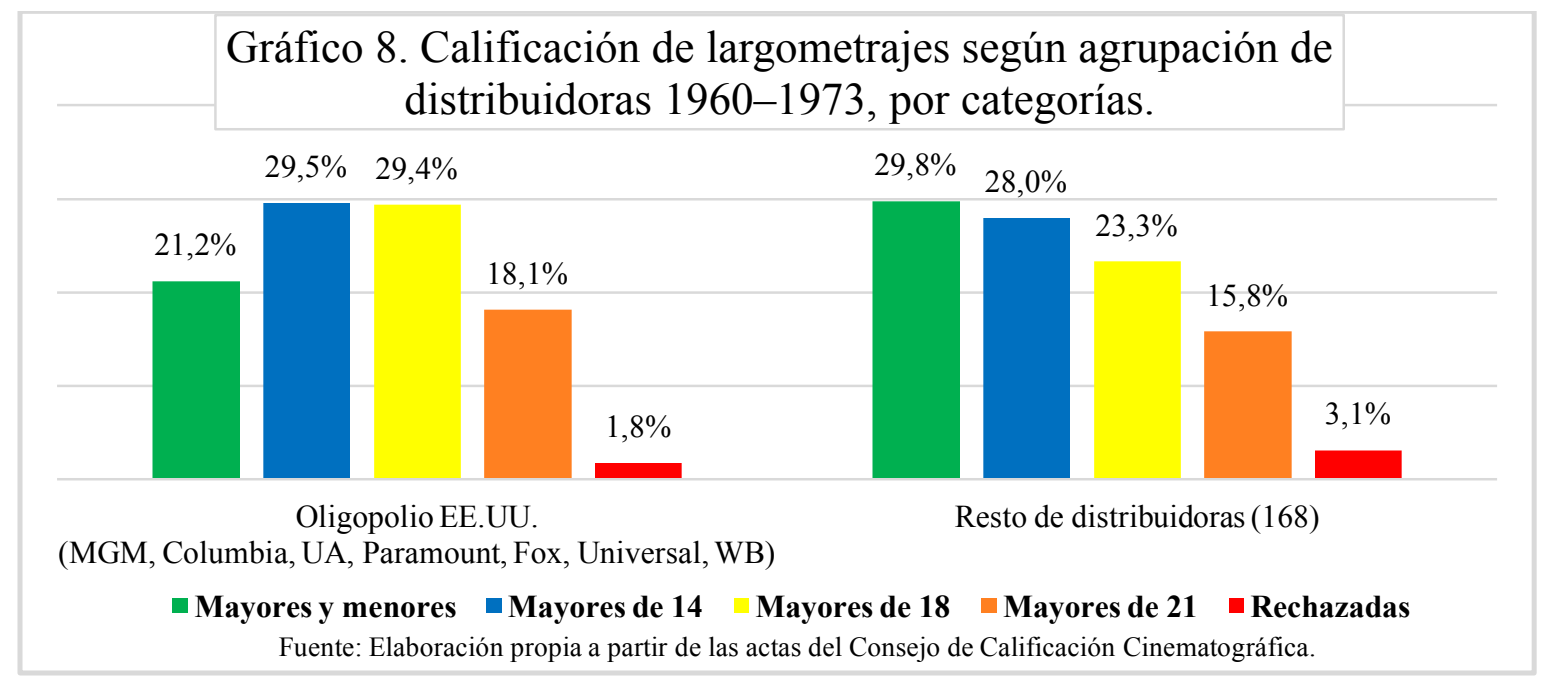

\subsubsection{Nacionalidad de las películas prohibidas}

De los 140 largometrajes rechazados, fue posible identificar el país de origen de 120 películas (ver gráfico $\mathrm{n}^{\circ} \mathrm{9}$ ), a partir de la información ofrecida por Internet Movie Database, IMDB ${ }^{13}$. Llama la atención el foco de las prohibiciones hacia cinematografías de segundo orden en términos de tamaño, como Italia y Francia. Con el 20\% y 17\% de los rechazos respectivamente, estimamos que su

13 Para simplificar la información, en el caso de las coproducciones (varios países) se incluyó solo el primer país indicado en IMDB. 
participación en los vetos podría constituir cerca del cuádruple y el doble de su participación en el mercado (respectivamente el 5 y 9\%14). Las cinematografías más fuertes en cambio, Estados Unidos y México, ocuparon proporciones menores de rechazo (18\% y 5\%) en relación a su tamaño estimativo ( $40 \%$ y 11,4\% del mercado respectivamente). Estos resultados están en línea con las sospechas expuestas en el párrafo anterior: un trato más preferente del Consejo hacia los actores más grandes de la plaza ${ }^{15}$. En ese sentido no deja de ser llamativo que, sumadas, las cinematografías sudamericanas constituyeran el $9 \%$ de los rechazos (la cuarta cinematografía más prohibida, si la tomamos como unidad). Por otro lado, sin embargo, una cinematografía habitualmente considerada como contrahegemónica para la cultura dominante local, la proveniente del bloque soviético, presenta niveles ínfimos de prohibición en este período: apenas una cinta polaca.

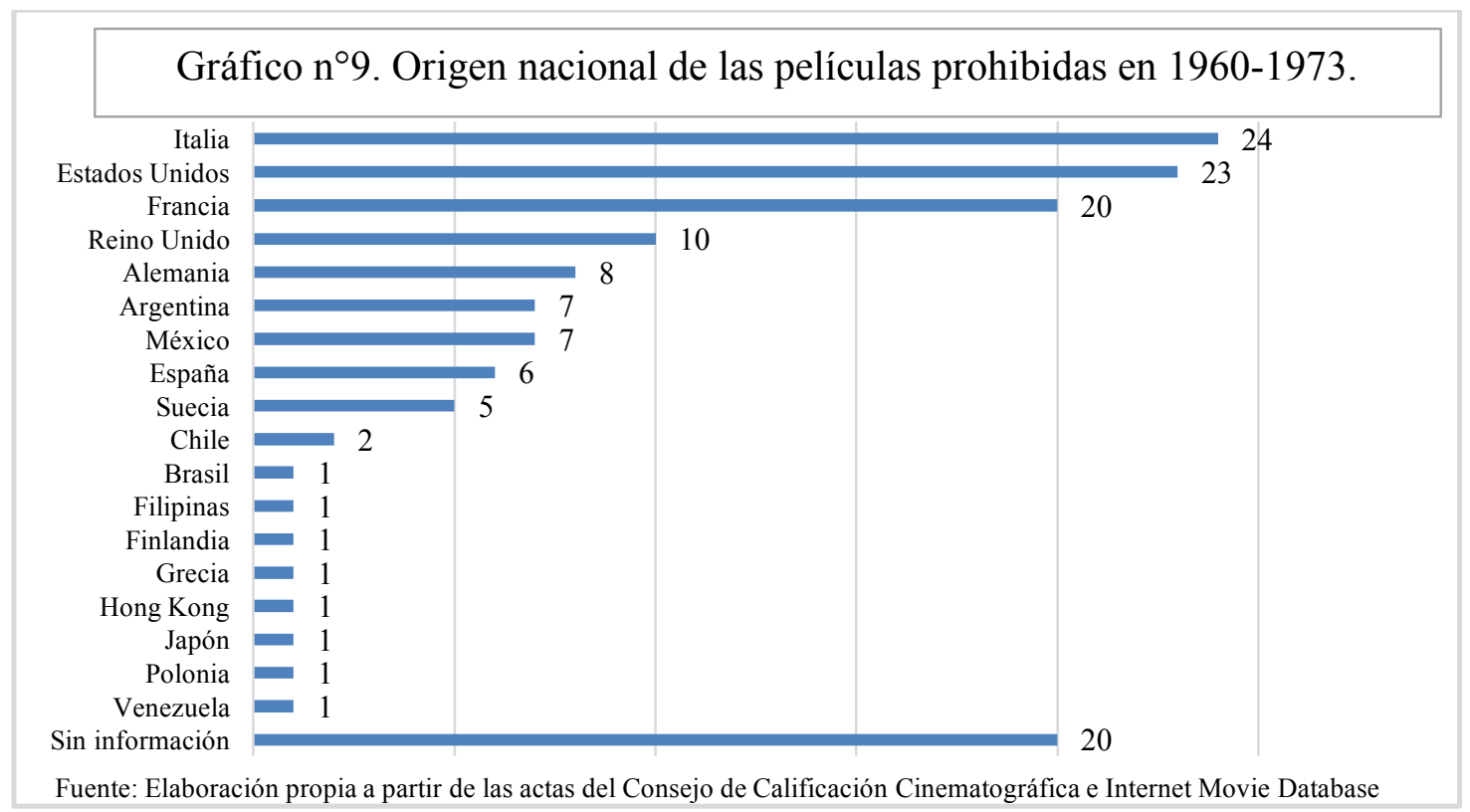

14 Para estimar la participación de cada industria en la cartelera chilena usamos las cifras de Jaime Busquet (1962, p. 49), quien contó 291 películas estrenadas en el primer semestre de 1960. Las ocho cinematografías más fuertes fueron: EEUU con el 39,9\% de los estrenos, México con $11,4 \%$, Alemania 10,3\%, Francia 8,9\%, Inglaterra 6,2\%, España 5,5\%, Italia 5,2\% y Argentina $4,1 \%$.

15 Ramírez (2013, p. 71) presenta datos similares para Argentina de inicios de la década de 1960. La calificación católica (no oficial) expresó reparos mayoritariamente a las cinematografías sueca, francesa e italiana, ocupando la estadounidense el último lugar en calificaciones negativas. 


\subsubsection{Por palabras clave de los títulos}

El análisis de cómo fueron calificadas las películas de acuerdo a sus palabras clave es bastante expresivo en cuanto a señalar un énfasis restrictivo hacia la cuestión erótica. Agrupamos la calificación de estas películas en tres categorías: menores de edad (MyM y +14), mayores de edad $(+18$ y +21$)$ y rechazadas (recordemos que la proporción porcentual de todo el corpus, respectivamente, fue de 54,8\%, 42,7\% y 2,5\%). En el campo de lo sexual y erótico ubicamos once palabras que podrían ser asociadas a ese tópico (tabla $\mathrm{n}^{\circ} 2$ ). Los términos más castigados fueron "sexo", "placer", "matrimonio" y "pasión", con menos del 7\% aprobado para menores de 18. "Sexo" además constituye el vocablo con mayor tasa de prohibición de toda la muestra, un $38 \%$.

\begin{tabular}{|c|c|c|c|c|}
\hline & $\begin{array}{c}\text { Cantidad } \\
\text { de } \\
\text { películas } \\
\text { (unidades) }\end{array}$ & $\begin{array}{c}\text { Mayores } \\
y \\
\text { menores } \\
+ \\
\text { Mayores } \\
\text { de } 14 \\
\end{array}$ & $\begin{array}{c}\text { Mayores } \\
\text { de } 18+ \\
\text { Mayores } \\
\text { de } 21\end{array}$ & Rechazos \\
\hline $\begin{array}{l}\text { Amor(es) } \\
(\text { amoroso/a(s)) }\end{array}$ & 194 & $35 \%$ & $59 \%$ & $6 \%$ \\
\hline Mujer(es) & 100 & $20 \%$ & $71 \%$ & $9 \%$ \\
\hline Amante(s) & 38 & $24 \%$ & $76 \%$ & $0 \%$ \\
\hline $\begin{array}{ll}\text { Pasión } \\
\text { apasionado) }\end{array}$ & 30 & $7 \%$ & $86 \%$ & $7 \%$ \\
\hline $\begin{array}{l}\text { Pecado(s) } \\
\text { (pecador/a(s)) }\end{array}$ & 29 & $24 \%$ & $69 \%$ & $7 \%$ \\
\hline Desnudo/a & 18 & $17 \%$ & $83 \%$ & $0 \%$ \\
\hline Novio/a(s) & 18 & $83 \%$ & $17 \%$ & $0 \%$ \\
\hline Sexo (sexual, sexy) & 16 & $6 \%$ & $56 \%$ & $38 \%$ \\
\hline Placer(es) & 16 & $6 \%$ & $81 \%$ & $13 \%$ \\
\hline Matrimonio & 13 & $0 \%$ & $100 \%$ & $0 \%$ \\
\hline Soltero/a(s) & 11 & $18 \%$ & $82 \%$ & $0 \%$ \\
\hline
\end{tabular}

Tabla ${ }^{\circ}{ }^{2}$. Calificación de películas con palabras asociadas a sexo, 1960-1973

Términos como "amor", "mujer", "amante", "pecado", "desnudo/a" y "soltero/a" fueron calificados para menores de 18 en una proporción de entre un sexto y un tercio. Solo "novio/a" presenta indicadores muy distintos a esta tendencia, al tener más de un $80 \%$ de aprobación para menores. En lo que podríamos calificar como crimen y violencia (tabla ${ }^{\circ} 3$ ), encontramos palabras castigadas, 
pero en general los resultados son mucho más equilibrados que en el tópico anterior. "Violencia", "crimen" y "matar" tienen índices bajos de aprobación para menores, en torno al tercio, es decir que la tasa de calificación para 18, 21 y rechazo casi los dobla. Sin embargo "muerte", "sangre" y "asesino" fueron calificadas para menores entre un 40\% y 50\%. "Guerra", "pistola" y "venganza" fueron mayoritariamente calificadas para menores de edad.

\begin{tabular}{|l|c|c|c|c|}
\hline & $\begin{array}{c}\text { Cantidad } \\
\text { de } \\
\text { películas } \\
\text { (unidades) }\end{array}$ & $\begin{array}{c}\text { Mayores } \\
\text { y } \\
\text { menores } \\
+ \\
\text { Mayores } \\
\text { de 14 }\end{array}$ & $\begin{array}{c}\text { Mayores } \\
\text { de 18+ } \\
\text { Mayores } \\
\text { de 21 }\end{array}$ & Rechazos \\
\hline $\begin{array}{l}\text { Muerte (muerto, } \\
\text { muertos) }\end{array}$ & 84 & $39 \%$ & $57 \%$ & $4 \%$ \\
\hline $\begin{array}{l}\text { Matar (maté, mató, } \\
\text { etc.) }\end{array}$ & 58 & $36 \%$ & $59 \%$ & $5 \%$ \\
\hline Sangre (sangrienta) & 54 & $43 \%$ & $52 \%$ & $5 \%$ \\
\hline Venganza (vengador) & 52 & $54 \%$ & $46 \%$ & $0 \%$ \\
\hline $\begin{array}{l}\text { Guerra (guerrero, } \\
\text { guerrillero) }\end{array}$ & 50 & $78 \%$ & $22 \%$ & $0 \%$ \\
\hline Pistola (pistolero) & 43 & $58 \%$ & $42 \%$ & $0 \%$ \\
\hline Asesino (asesinato) & 42 & $48 \%$ & $52 \%$ & $0 \%$ \\
\hline Crimen (criminal) & 28 & $32 \%$ & $68 \%$ & $0 \%$ \\
\hline Violencia (violento/a) & 18 & $28 \%$ & $66 \%$ & $6 \%$ \\
\hline
\end{tabular}

Tabla $^{\circ} 3$. Calificación de películas con palabras asociadas a crimen y violencia, 1960-1973.

Para dimensionar mejor las cifras es útil mencionar algunas de las palabras mejor tratadas por el Consejo, es decir que están por sobre el promedio general. Allí encontramos "misterio" (92/8/o), "loco/a" (84/16/o), "viaje" (74/26/o), "aventura" (69/31/o), hijo/a (66/34/o), "mundo" (59/34/7) y "secreto/a" (58/39/3). Por último, uno de los datos más llamativos de toda la muestra es que a diferencia de "mujer" (20/71/9), "hombre" tuvo un trato bastante similar al del promedio general, 52/48/o.

\subsubsection{Por consejeros}

Al desglosar las votaciones según los integrantes del Consejo, vemos que hay elementos que indican ciertos consensos grupales, sin embargo los elementos de 
disenso resultan muy esclarecedores ${ }^{\mathbf{1 6}}$. Partamos señalando que la gran mayoría de sesiones registraron votaciones unánimes, es decir todos los revisores presentes (generalmente cuatro) votaron la misma calificación. De las 4934 sesiones donde se explicitan los votos individuales de cada consejero presente, el $78 \%$ se resolvió de manera unánime y el $22 \%$ por mayoría/minoría. Ahora bien, detrás de esta homogeneidad se ven importantes diferencias.

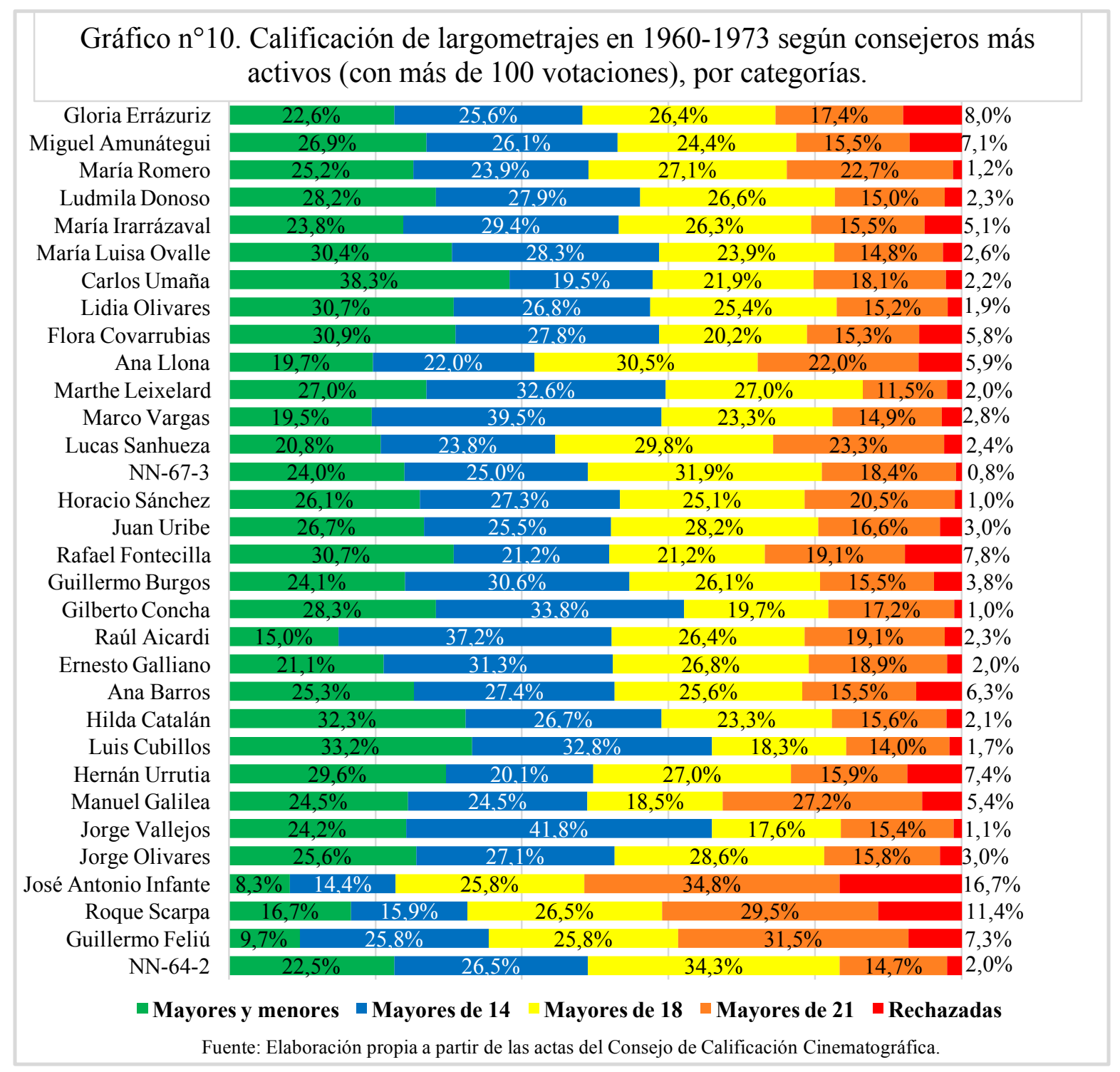

${ }^{16}$ La lista de consejeros más activos ofrecida en esta sección (gráfico $\mathrm{n}^{\circ} 10$ ) difiere de la anterior (gráfico $\mathrm{n}^{\circ} 4$ ), pues esa estaba basada en la cantidad de presencias en sesiones (23.402 firmas en total) y ésta se basa en cantidad de presencias con voto explícito (21.996 votaciones). Esta diferencia se origina pues a veces los consejeros firmaban asistencia pero se olvidaban de estampar su calificación. 
La distribución total de los votos fue de la manera siguiente. De un total de 21.996 votos emitidos en el período, el 52,9\% se lo llevaron las categorías de menores de edad, el $43 \%$ fue a mayores, mientras que el 4,1\% fueron votos de prohibición ${ }^{17}$. El sexo de los consejeros parece no ser un factor influyente en el voto. Vemos que hombres y mujeres calificaron casi de la misma manera (53,2/42,4/4,4 versus 52,8/43,2/4). Donde sí se ven diferencias es entre los integrantes más y menos activos. Hicimos foco en los 32 revisores con más de 100 calificaciones (ver gráfico $\mathrm{n}^{\circ} 10$ ), responsables del 97,5\% del total de votaciones. Los tres revisores más activos, Gloria Errázuriz, Miguel Amunátegui y María Romero, en conjunto ejercieron su voto en la proporción 50,1/44,4/5,5 (más estrictos que el promedio en las tres categorías), mientras que los otros 29 lo hicieron en 54,1/42,6/3,3 (menos estrictos que el promedio en las tres categorías). La diferencia entre esos dos grupos es significativa en los rechazos: los tres consejeros más fuertes tuvieron una tasa de prohibiciones 66\% más alta que el resto. Y precisemos que ese promedio de vetos resulta algo engañoso ya que Romero, con su moderado 1,2\% de rechazos, hace descender bastante las cifras de los otros dos, que son muy altas ( $8 \%$ y 7,1\% respectivamente, la tercera y séptima más alta entre los 32 consejeros más fuertes). El desempeño de Romero da la impresión de ser poco estricto por ese factor, pero un análisis del conjunto de sus calificaciones indica otra cosa: su proporción de películas aprobadas para menores de 18 es casi igual a las aprobadas para mayores (49\% versus 49,8\%; recordemos que el promedio de los 32 revisores arroja casi diez puntos porcentuales de diferencia) y su tasa de calificación para mayores de 21 $(22,7 \%)$ es la sexta más alta entre los 32 consejeros (ello hace pensar en una política sistemática de su parte en cuanto a pasar a mayores de 21 las cintas que la mayor parte de sus colegas vetaban). Otra forma de organizar los resultados es por rango de los consejeros. Aislamos los resultados de los seis miembros que más sesiones presidieron (por sobre 300 sesiones): Romero, Sanhueza,

\footnotetext{
${ }_{17}$ Evidentemente estas cifras difieren con las de las calificaciones globales del corpus, pues se trata de votos individuales que, combinados en mayoría/minoría, generan los resultados finales de calificación.
} 
Galliano, Fontecilla, Concha y Vargas. Su proporción de votos fue de 51,5/46,3/2,2 (los otros 26 arrojaron 53,2/42,2/4,6). Se puede afirmar que se trata de un grupo de consejeros no demasiado diferente al global, aunque sí se advierte en ellos una suerte de tendencia a depositar en categorías para 18 y 21 las obras que el resto ponía en rechazo. El comportamiento promedio de estos mandos medios (todos menos Concha presidieron las sesiones en calidad de suplentes) resalta aún más si atendemos a las cifras de los altos mandos. Los presidentes titulares del Consejo de Censura Cinematográfica entre 1960 y 1971, Guillermo Feliú y Roque Scarpa, están en el podio de los revisores más estrictos de la lista de 32. Feliú votó en la proporción 35,5/57,2/7,3 y Scarpa lo hizo en 32,5/56,1/11,4. Respectivamente, son la tercera y segunda tasas más bajas de aprobación para menores, la segunda y tercera tasas más altas de aprobación para mayores, y la sexta y segunda tasas más altas de prohibición. En pocas palabras, votaban por prohibir algo así como una de cada diez películas que revisaban. Llama la atención el enorme contraste con el siguiente director de la DIBAM, Gilberto Concha (en el cargo entre 1971 y 1973), quien resultó ser uno de los revisores menos severos del plantel, con votaciones en la proporción de $62,2 / 36,8 / 1$. No queda sino concluir en un vínculo entre gobierno y desempeño de los integrantes del Consejo. Sumados, los cuatro consejeros nombrados durante el gobierno de la Unidad Popular (Gilberto Concha, Luis Cubillas, Jorge Vallejos y Sergio González) votaron en una proporción muy alejada al promedio global: 64,3/34,6/1,1. Es en este grupo que encontramos los números menos restrictivos de la lista. Concha, Cubillas y Vallejos constituyen la segunda, sexta y cuarta tasa más baja de rechazos, respectivamente, la primera, segunda y cuarta cifra más baja de calificación para mayores y la tercera, primera y segunda tasa más alta de aprobación para menores de edad ${ }^{18}$. En resumen, se

\footnotetext{
${ }^{18}$ Debido a que no contamos con la adscripción institucional de la mayoría de los consejeros, no podemos establecer de manera consistente, por ejemplo, cómo ejercieron el voto los representantes católicos. Los cuatro que conocemos (Errázuriz, Amunátegui, Irarrázaval y Ovalle) votaron en una lógica de 52,3/41,3/6,4 mientras los otros 28 de la lista analizada lo hicieron en proporción de 53,8/42,8/3,3, es decir las diferencias se dan solo en los rechazos. De hecho no es evidente asumir tendencias grupales de tipo ideológico-institucional: por ejemplo
} 
puede afirmar que en el equipo de revisores del período hubo un consenso mayoritario, que efectivamente existieron importantes diferencias individuales (ligadas en parte al factor gobierno), pero que por su tamaño no alcanzaron a modificar grandemente los promedios. Por último, es claro como el plantel de consejeros estuvo dominado, sea por su frecuencia, sea por su status, por los revisores más estrictos del equipo.

\section{Conclusiones}

El análisis cuantitativo del trabajo ejercido por el Consejo de Censura Cinematográfica de Chile arroja en términos generales un fuerte impacto en el mercado de películas en cuanto a excluir fuertemente a los públicos menores de edad de más de la mitad de la cartelera. Ahora bien, detrás de ese comportamiento global se observan diferencias bastante marcadas que inhabilitan la idea de una institución monolítica. En primer lugar, los resultados variaron bastante año a año y entre los diferentes gobiernos del período, notándose una honda brecha entre el gobierno de la derecha (Jorge Alessandri) y el de la izquierda (Salvador Allende). En relación a la calificación según distribuidora y origen nacional de las películas, se observa una actitud más benévola del CCC hacia los agentes fuertes del mercado. En cuanto a los contenidos, se advierte una mayor dureza del Consejo con los estímulos eróticos que con los de crimen y violencia. Por último, los datos indican que, si bien la mayor parte de las sesiones se resolvieron de manera unánime, al interior del plantel de consejeros existían importantes diferencias, sea según status, nivel de participación o período de gobierno. En ese sentido, este trabajo ha buscado despejar las visiones generalizantes que ponen más oscuridad que luz sobre los fenómenos culturales. Olave y De La Parra (2001, p. 18) se refieren al Consejo como una unidad monolítica ("feudo oscurantista y mercantil”, "reducto gestor y votación para mayores. 
de infinidad de arbitrariedades”), quizás porque les resultó atractivo el mito de la oscuridad. De hecho, califican a la institución como "una de las zonas más sombrías y desconocidas de la administración cultural de las últimas décadas”, afirmación que de alguna manera da luz verde a cualquier juicio incontrastable. A partir de lo revisado en este trabajo, creemos que el Consejo de Censura estaba lejos de ser una especie de software programado e invariable. En el acto de calificación de películas comparecían muchos factores diversos, no solo la pertenencia ideológica o institucional del consejero. También eran decisivos el status del sujeto, el volumen de su participación, el contenido de las obras revisadas, los dueños de esas obras y, por cierto, el momento histórico y la administración de turno. Esa compleja red de interacciones, más que parecerse al funcionamiento de un algoritmo, remite al carácter contingente de cualquier oficina gubernamental.

\section{Referencias bibliográficas}

Archivo del Consejo de Calificación Cinematográfica, Ministerio de Educación, Gobierno de Chile (volúmenes de Actas).

Biltereyst, D. \& Vande Winkel, R. (eds.) (2013). Silencing Cinema. Film censorship around the world. Nueva York: Palgrave Macmillan.

Black, G. (1999). La cruzada contra el cine (1940-1975). Madrid: Cambridge University.

Busquet, J. (1962). Libertad de expresión y censura cinematográfica. Memoria para optar al título de Periodista de la Universidad de Chile.

Ministerio de Educación. Decreto con Fuerza de Ley 37. Santiago, Chile, 1 diciembre 1959.

Ethis, E. (2014). Sociologie du cinéma et de ses publics. París: Armand Colin.

Iturriaga, J. (2015). La masificación del cine en Chile 1907-1932. La conflictiva construcción de una cultura plebeya. Santiago: LOM.

Iturriaga, J. \& Donoso, K. (2018). Los debates sobre la censura cinematográfica en Chile, 1959-1973. Tiempo Histórico, 16, 137-156.

Maltby, R., Biltereyst, D. \& Meers, P. (2011). Explorations in new cinema history. Approaches and case studies. Chichester: Wiley-Blackwell. 
Maltby, R. (2011). New cinema histories. En Maltby, R., Biltereyst, D. \& Meers, P. (eds.), Explorations in new cinema history. Approaches and case studies (pp. 3-40). Chichester: Wiley-Blackwell.

Olave, D. y De la Parra, M. (2001). Pantalla prohibida. Censura cinematográfica en Chile. Santiago: Mondadori.

Paranaguá, P. (2003). Tradición y modernidad en el cine de América Latina. Madrid: Fondo de Cultura Económica.

Ramírez, F. (2016). Noches de sano esparcimiento. Estado, católicos y empresarios en la censura al cine en Argentina 1955-1973. Buenos Aires: Libraria. 